\title{
Optimization of Delamination and Thrust Force in the Drilling Process of Nanocomposites
}

\author{
Nilay Kucukdogan ${ }^{1 *}$ \\ ${ }^{1 *}$ Manisa Celal Bayar University, Hasan Ferdi Turgutlu Technology Faculty, Departmant of Mechatronics Engineering, Manisa, Turkey, (ORCID: 0000-0003-4375- \\ 0752),nilay.ozturk@cbu.edu.tr
}

(International Conference on Design, Research and Development- 15 - 18 Aralık 2021)

(DOI: 10.31590/ejosat.1040182)

ATIF/REFERENCE: Kucukdogan, N., (2021). Optimization of Delamination and Thrust Force in the Drilling Process of Nanocomposites. European Journal of Science and Technology, (32), 807-815.

\begin{abstract}
A new design optimization technique is presented to improve the analytical performance of the drilling process of graphene oxide nanocomposites. A detailed study was conducted for modeling-design-optimization of the drilling process using multiple nonlinear neuroregression analyses for this goal. The data were slected from a literature study for this objective. The accuracy of the predictions of the nine potential functional structures presented for modeling the data was tested using a hybrid neuro-regression-based technique. Model selections to determine the objective functions were made by controlling the $\mathrm{R}^{2}$ values, limit values, and statistical results, respectively. The selected models were used in the optimization studies of delamination and thrust force values with four different optimization algorithms. The results show that the $\mathrm{R}^{2}$ training and $\mathrm{R}^{2}$ training-adjust values give good results in the nine models as objective functions.

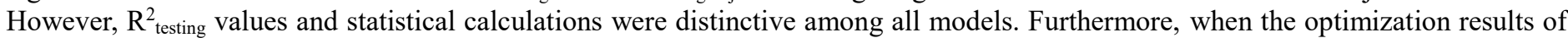
the third-order polynomial and logarithmic models for both responses were compared to the reference study's results, it was observed that the current results were more closer to the test results.
\end{abstract}

Keywords: Nano-composites, Drilling prosess, Neuro-regression modeling, Optimization.

\section{Nanokompozitlerin Delme Prosesinde Delaminasyon ve İtme Kuvvetinin Optimizasyonu}

\begin{abstract}
$\ddot{O} \mathbf{z}$
Grafenoksit nano-kompozitlerin delme işleminin analitik performansını geliştirmek için yeni bir tasarım optimizasyon tekniği sunulmuştur. Bu amaçla çoklu doğrusal olmayan nöro-regresyon analizleri kullanılarak delme sürecinin modelleme-tasarımoptimizasyonu için detaylı bir çalışma yapılmıştır. Veriler bu amaç için bir literatür çalışmasından seçilmiştir. Verileri modellemek için sunulan dokuz potansiyel fonksiyonel yapının tahminlerinin doğruluğu, hibrit nöro-regresyon tabanlı bir teknik kullanılarak test edilmiştir. Amaç fonksiyonlarını belirlemek için yapılan model seçimleri sırasıyla $\mathrm{R}^{2}$ değerleri, sınır değerleri ve istatistiksel sonuçlar kontrol edilerek yapılmıştır. Seçilen modeller dört farklı optimizasyon algoritması ile delaminasyon ve itme kuvveti değerlerinin optimizasyon çalışmalarında kullanılmıştır. Sonuçlar, $\mathrm{R}^{2}$ eğitim ve $\mathrm{R}^{2}$ eğitim-ayarlanmış değerlerinin amaç fonksiyonu olarak dokuz modelde iyi sonuçlar verdiğini göstermiştir. Ancak, $\mathrm{R}^{2}$ test değerleri ve istatistiksel hesaplamalar tüm modeller arasında ayırt edici olmuştur. Ayrıca her iki çıktı için üçüncü dereceden polinom ve logaritmik modellerin optimizasyon sonuçları referans çalışmanın sonuçlarıyla karşılaştırıldığında, mevcut sonuçların test sonuçlarına daha yakın olduğu görülmüştür.
\end{abstract}

Anahtar Kelimeler: Nano kompozitler, Delme prosesi, Nöro-regresyon modellemesi, Optimizasyon.

\footnotetext{
*Corresponding Author: nilay.ozturk@cbu.edu.tr
} 


\section{Introduction}

In the twenty-first century, polymer composites have become the main structural materials in many industrial areas due to their lightness, high strength, good corrosion resistance, and strength that can be improved. Among the most significant advantages of these materials are their developable strength properties (Adeniyi, Ighalo, \& Onifade, 2019; Equbal et al., 2020; Sharma, Bhandari, Aherwar, \& Rimašauskienė, 2020; Suriani et al., 2021; Wang et al., 2021). In addition to the advantages, there are drawbacks associated with the manufacture and processing of these materials. This situation has prompted researchers to conduct indepth research on processing behaviours. Analytical and numerical models are presented to reveal more precise results (Anand, Alagumurthi, Elansezhian, Palanikumar, \& Venkateshwaran, 2018; Ferreira et al., 2018; Papageorgiou, Kinloch, \& Young, 2017; Saoudi, Zitoune, Mezlini, Gururaja, \& Seitier, 2016).

The use of nano-scale fillers in composites enables significant changes in polymer composites. At least one typical length scale on the order of nanometers exists in nano-scale fillers. These materials can be examined under three basic classes as zero-dimensional spherical, 1-dimensional fibrous, and 2dimensional layered (Idumah \& Obele, 2021; Pramanik et al., 2021). In this classification, graphene is classified as 2dimensional, while carbon fibers and nanotubes are classified as 1-dimensional. In recent years, graphene has high elasticity $(\sim 1 \mathrm{TPa})$, large specific surface area $\left(2600 \mathrm{~m}^{2} / \mathrm{g}\right)$, high electron mobility at room temperature $\left(260,000 \mathrm{~cm}^{2} / \mathrm{V}_{\mathrm{s}}\right)$, high thermal conductivity $(5100 \mathrm{~W} / \mathrm{mK})$, good electrical conductivity, it has found a place in many applications due to its attractive features (Hareesha, Yogesha, Naik, \& Saravanabavan, 2021; Papageorgiou et al., 2017). Also, graphene oxide-based composites are promising possibilities for a variety of industrial applications, including aircraft components and electronics like supercapacitors, transistors, electrophoresis, and gas sensors, among others (Kim et al., 2021; Roshan, Sheikhi, Haghighi, \& Padidar, 2019).The development of graphene-based composite materials with desirable characteristics is also a hot topic of study (Hou, Gao, Wang, Blackwood, \& Teo, 2020; Lawal, 2020; W. Yu, Sisi, Haiyan, \& Jie, 2020). Due to the increasing interest in the study of its mechanical properties, it is very popular both in different fields of industry and in academic studies, alongside growing commercialization studies have progressed quite rapidly (Papageorgiou, Li, Liu, Kinloch, \& Young, 2020; Sanes, Sánchez, Pamies, Avilés, \& Bermúdez, 2020; Soleymani Eil Bakhtiari et al., 2020).

Although it is seen that better properties are not obtained thanks to the use of graphene oxide in the composite structure compared to graphene, it is preferred because it can be obtained more easily and in high volumes during the preparation process of nano-composites, and it is easy to disperse in water and other solvents (Hou et al., 2020). Appropriate processing methods should also be chosen for the creation of final products with distinguishing characteristics such as low weight, high strength, and excellent hardness. In the manufacturing industry, it is used as secondary processes in grinding, honing, and lapping processes to achieve the desired quality, especially in drilling and turningmilling processes to obtain the final product. Although the drilling process appears to be one of the basic routine operations, it is critical in terms of assembling the parts within the desired tolerances and achieving the desired high quality (Srinivasan,
Thirumurugaveerakumar, Nagarajan, Raffic, \& Babu, 2021; Thakur \& Singh, 2021).

Among the machining operations performed after the production of composite materials, the drilling required for bolting, riveting, and screwing operations is performed using conventional machining techniques used for metallic materials (Saoudi et al., 2016). Drilling operations performed with computer-controlled or conventional drilling machines cause damages such as matrix cracks, fiber breaks, delamination, heatinduced distortions, and abrasion (Caggiano, 2018; R. Yu \& Pandolfi, 2008).

In drill and end mill applications, where drilling operations are frequently performed, the selection of inserts also gains importance. Delamination is the most destructive damage situation, as it directly affects the final product's properties such as durability, load-carrying capacity, and hardness (Khan \& Kim, 2011). For the proper performance of drilling operations, it is critical to reveal the limits of machinability and to perform parametric optimization. There are few studies on the machinability of nanocomposites and the optimization of processing performance in the literature. According to the current research, it is revealed that feed rate, delamination $(\mathrm{Fd})$ and thrust force (Th) are the most important outputs to reach the optimum values of the drilling process. It is critical to determine the appropriate parameters so that the final product is free of damage, errors, and falls within the desired tolerances. The Fd factor $(\mathrm{Fd})$ is often used to calculated using Eq. 1. The maximum diameter of the damaged area $\left(D_{\max }\right)$ is used in the equation to represent the nominal hole diameter (D) (Kumar, Verma, \& Debnath, 2020).

$$
\mathrm{F}_{\mathrm{d}}=\mathrm{D}_{\max } / \mathrm{D}
$$

The optimization approach for delamination research of nanocomposites begins with mathematical modeling. As a result, researchers use regression analysis (RA), response surface methodology (RSM), artificial neural networks (ANN), ANN and combined compromise solution, a hybrid module of the combined compromise solution, and the principle component analysis method to try to distinguish mathematical models (Alavitabari, Mohamadi, Javadi, \& Garmabi, 2021; Kumar \& Verma, 2021a, 2021b, 2021c). The obtained mathematical model also corresponds to the predicted objective function of the optimization problem for nanocomposites delamination study. When all of these studies are examined in terms of modelingdesign-optimization, it is discovered that the developed models have no limitation control.

The optimization process begins after obtaining sufficient mathematical models. Particle Swarm (PS), Simulated Annealing (SA) and Genetic Algorithm (GA) are generally used to optimize the parameters of analytical systems. Moghri et al. (2014) used GA to optimize the process parameters to minimize surface roughness in the drilling process of nanocomposite (Moghri, Madic, Omidi, \& Farahnakian, 2014). After the optimization studies, the minimum surface roughness values were obtained at the low feed rate and medium spindle speed level. Kumar et al. (2020) performed regression analysis to reduce $\mathrm{Fd}$ and Th during drilling of graphene oxide/carbon fiber reinforced polymer nanocomposites and examined the parameter effects of weight $\%$ of graphene-oxide (GO), spindle speeds $(\mathrm{S})$, and feed rate $(\mathrm{F})$. They suggested a parametric set as $\mathrm{S}=2400 \mathrm{rpm}, \mathrm{F}=80 \mathrm{~mm} / \mathrm{min}$ and wt. $\% \mathrm{GO}=1 \%$ with their optimization study with SA algorithm. At these parameters, they found that delamination was improved as $0.903 \%$ and Th was $4.517 \%$ (Kumar et al., 2020). 
Kharwar and Verma (2021) studied the optimization of surface roughness, cutting force, and material removal rate values with the Gray wolf algorithm in the drilling process of nanocarbon polymer composites. They obtained 2.5, 6.5 and $5.9 \%$ improvement in surface roughness, cutting force, and material removal rate values with optimum parameters, respectively (Kharwar \& Verma, 2021). Kesarwani et.al (2021), milling experiments of carbon nano tube (CNT)/Epoxy nanocomposites used a hybrid methodology of Gray theory and the Ant Lion Optimizer algorithm. They found that the feed rate and \%CNT were the most effective factors on their milling performance (Kesarwani, Pratap, Kumar, Verma, \& Singh, 2021).

When these literature studies for optimization purposes are analyzed, it is clear that some methodologies are insufficient:

- In the optimization process, some standard procedures (e.g., sequential quadratic, Lagrange, derivative-based methods) were applied. They are, however, insufficiently resilient for exact outcomes, particularly in the optimization of engineering systems with several local extremes.

- As an objective function for optimization procedures, all studies on drilling process modeling and optimization use only one or two different regression models. The fundamental difficulty is the additional calculation of the model's $\mathrm{R}^{2}$ value for experimental research. A high $\mathrm{R}^{2}$ value, on the other hand, does not describe all of the physical phenomena that occur during the engineering process. The $\mathrm{R}^{2}$ number represents how close the fitted model's results are to the experimental data. To put it another way, a high or low $\mathrm{R}^{2}$ number for real-world systems does not always imply a good fit. Aside from this, the model describes the experimental data, not the fundamental behavior of the events. As a result, additional drilling process modeling experiments with various regression types must be attempted.

- Furthermore, the model function should be bounded, which is a crucial aspect. Boundedness is essential in the realistic modeling of engineering systems since all engineering parameters are finite. As a result, before beginning the optimization process, ensure that the selected models are also bounded for engineering parameter intervals.

- The algorithms reliability, sensitivity, and robustness are not taken into account in the published studies on drilling process optimization. However, revealing the basic behaviors of stochastic search systems is crucial.

For these reasons, we have developed a modeling-designoptimization technique for optimizing drilling input parameters of nanocomposites. This method was developed based on a literature review (Kumar et al., 2020), which found that the Box-Behnken design and regression analysis were used to achieve the mimimum values of $\mathrm{Fd}$ and $\mathrm{Th}$. Modeling and optimization work was carried out in 3 steps. (i) A thorough investigation of several nonlinear neuro-regression analyses for the immobility percentage problem (output), including linear, quadratic, trigonometric, and logarithmic forms, was conducted. (ii) The proposed models' boundedness was examined to ensure that they could generate realistic values. (iii) stochastic optimization techniques (DE, NM, $\mathrm{RS}$, and SA) were applied methodically to the various direct search methods.

\section{Material and Method}

\subsection{Modeling and Statistical analysis}

In the modeling phase, a hybrid method combining the benefits of regression analysis and artificial neural networks was used to test the accuracy of the predictions. In this method, all of the data is divided into two sets, each containing $80 \%$ and $20 \%$ of the total data, with the first portion used for training and the second for testing. The goal of the training process is to minimize the difference between the experimental and predicted values by adjusting the regression models and their coefficients, which are listed in Table 1.

Table 1. Multiple regression model forms.

\begin{tabular}{|c|c|c|}
\hline Model Name & $\begin{array}{l}\text { Nomen } \\
\text { clature }\end{array}$ & Formula \\
\hline Multiple linear & $\mathrm{L}$ & $Y=\sum_{i=1}^{3}\left(a_{i} x_{i}\right)+c$ \\
\hline $\begin{array}{l}\text { Second order } \\
\text { multiple non-linear }\end{array}$ & SON & $\begin{array}{l}Y=\sum_{k=1}^{3} \sum_{j=1}^{3}\left(a_{j} x_{j} x_{k}\right)+ \\
\sum_{i=1}^{3}\left(a_{i} x_{i}\right)+c\end{array}$ \\
\hline $\begin{array}{l}\text { Third order } \\
\text { multiple non-linear }\end{array}$ & TON & $\begin{array}{l}Y= \\
\sum_{l=1}^{3} \sum_{m=1}^{3} \sum_{p=1}^{3}\left(\beta_{l} x_{l} x_{m} x_{p}\right) \\
\sum_{k=1}^{3} \sum_{j=1}^{3}\left(a_{j} x_{j} x_{k}\right)+ \\
\sum_{i=1}^{3}\left(a_{i} x_{i}\right)+c\end{array}$ \\
\hline $\begin{array}{l}\text { First order } \\
\text { trigonometric } \\
\text { multiple non-linear }\end{array}$ & FOTN & $\begin{array}{l}Y=\sum_{i=1}^{3}\left(a_{i} \operatorname{Sin}\left[x_{i}\right]+\right. \\
\left.a_{i} \operatorname{Cos}\left[x_{i}\right]\right)+c\end{array}$ \\
\hline $\begin{array}{l}\text { Second order } \\
\text { trigonometric } \\
\text { multiple non-linear }\end{array}$ & SOTN & $\begin{array}{l}Y=\sum_{i=1}^{3}\left(a_{i} \operatorname{Sin}\left[x_{i}\right]+\right. \\
\left.a_{i} \operatorname{Cos}\left[x_{i}\right]\right)+ \\
\sum_{j=1}^{3}\left(\beta_{j} \operatorname{Sin}^{2}\left[x_{j}\right]+\right. \\
\left.\beta_{j} \operatorname{Cos}^{2}\left[x_{j}\right]\right)+c\end{array}$ \\
\hline $\begin{array}{l}\text { Third order } \\
\text { trigonometric } \\
\text { multiple non-linear }\end{array}$ & TOTN & $\begin{array}{l}Y=\sum_{i=1}^{3}\left(a_{i} \operatorname{Sin}\left[x_{i}\right]+\right. \\
\left.a_{i} \operatorname{Cos}\left[x_{i}\right]\right)+ \\
\sum_{j=1}^{3}\left(\beta_{j} \operatorname{Sin}^{2}\left[x_{j}\right]+\right. \\
\left.\beta_{j} \operatorname{Cos}^{2}\left[x_{j}\right]\right)+ \\
\sum_{k=1}^{3}\left(\gamma_{k} \operatorname{Sin}^{3}\left[x_{k}\right]+\right. \\
\left.\gamma_{k} \operatorname{Cos}^{3}\left[x_{k}\right]\right)+c\end{array}$ \\
\hline $\begin{array}{l}\text { First order } \\
\text { logarithmic } \\
\text { multiple non-linear }\end{array}$ & FOLN & $Y=\sum_{i=1}^{3}\left(a_{i} \log \left[x_{i}\right]\right)+c$ \\
\hline $\begin{array}{l}\text { Second order } \\
\text { logarithmic } \\
\text { multiple non-linear }\end{array}$ & SOLN & $\begin{array}{l}Y= \\
\sum_{k=1}^{3} \sum_{j=1}^{3}\left(a_{j} \log \left[x_{j} x_{k}\right]\right)+ \\
\sum_{i=1}^{3}\left(a_{i} \log \left[x_{i}\right]\right)+c\end{array}$ \\
\hline $\begin{array}{l}\text { Third order } \\
\text { logarithmic } \\
\text { multiple non-linear }\end{array}$ & TOLN & $\begin{array}{l}Y= \\
\sum_{l=1}^{3} \sum_{m=1}^{3} \sum_{p=1}^{3}\left(\beta_{l} \log \left[x_{l} x_{n}\right.\right. \\
\sum_{k=1}^{3} \sum_{j=1}^{3}\left(a_{j} \log \left[x_{j} x_{k}\right]\right)+ \\
\sum_{i=1}^{3}\left(a_{i} \log \left[x_{i}\right]\right)+c\end{array}$ \\
\hline
\end{tabular}

To determine the relationships between neuro-regression models and experimental data, statistical analyses of coefficient of determination $\left(\mathrm{R}^{2}\right)$, mean square error (RMSE), mean absolute error (MAE), and model efficiency (ME) for each model were used. Furthermore, the lowest and highest values were calculated while adhering to the experimental parameter limits using the prepared models. 
Root mean square error: $R M S E=\sqrt{\frac{1}{n} \sum_{i=1}^{n}\left(X_{A, i}-X_{P, i}\right)^{2}}$

Coefficient of determination: $R^{2}=1-\frac{\sum_{i=1}^{n}\left(X_{A, i}-X_{P, i}\right)^{2}}{\sum_{i=1}^{n} X_{P, i}^{2}}$

Mean absolute error: $M A E=\frac{1}{n} \sum_{i=1}^{n}\left(X_{A, i}-X_{P, i}\right)$

Model efficiency: $M E=1-\frac{\sum_{i=1}^{n}\left(X_{A, i}-X_{P, i}\right)^{2}}{\sum_{i=1}^{n}\left(X_{A, i}-\bar{X}_{P, i}\right)^{2}}$

where, $\mathrm{X}_{\mathrm{A}}$ is actual data and $\mathrm{X}_{\mathrm{P}}$ is predicted data.

Following this, the stage of selecting the regression model was carried out. This process is done in three basic steps. (i) $\mathrm{R}^{2}$ values are calculated for each model, and those less than 0.9 are eliminated. (ii) To determine whether the model is realistic, the predicted cutoff values of the candidate models should differ by at most $20 \%$ from the actual results. Models that fail to meet these values are eliminated. (iii) RMSE and MA should be close to zero, and ME should be close to one, from the statistical results of the models that passed the previous stages.

\subsection{Optimization}

In essence, structural optimization can be defined as achieving the optimal designs by minimizing the stated single or multi-objective that corresponds to all constraints. There are two types of optimization techniques: traditional and nontraditional. Traditional optimization approaches, such as restricted variation and Lagrange multipliers, only work for continuous and differentiable functions. Because of the peculiarity of engineering design challenges, typical optimization approaches cannot be employed. In these situations, stochastic optimization approaches like GA, PS, and SA algorithms are advantageous. However, the exact solution cannot be reached due to stochastic methods, hence employing many methods with diverse phenomenological bases for the same optimization issue boosts the result's trustworthiness (Aydin \& Artem, 2011).

Some difficulties in mathematical optimization problems can be listed in four main items: (i) multiple nonlinear objective functions, (ii) objective functions having many local extremum points, (iii) mixed-integer(discrete)- continuous nature of the design variables, and (iv) nonlinear constraints. The issue posed in the first three problems is one of the optimization scenarios covered in this paper. Four different optimization methods (DE, NM, SA, and RS) were used to solve the optimization difficulties. Detail description of all algorithms can also be found in (Erten, Deveci, \& Artem, 2020).

\subsubsection{Differential Evolution algorithm}

The Differential Evolution algorithm is an evolutionary method that allows for alternate solutions for complex machining processes such as slicing, milling, grinding, and wear and drilling. Initialization, mutation, crossover, and selection are the four key steps. Because of the algorithm's stochastic nature, changing the variables (scaling factor, crossover, and population size) can vary the optimum outcome. It should be emphasized that the DE algorithm is computationally expensive because it continuously analyzes a population of solutions rather than a single solution at each iteration. It finds the global optimum of the objective function in a generally resilient and efficient manner. However, finding the global optimum is not assured (Savran \& Aydin, 2018).

\subsubsection{Nelder-Mead algorithm}

The Nelder-Mead (NM) algorithm is a traditional local search strategy created for unconstrained optimization problems in the first place (Nelder \& Mead, 1965). It is noteworthy to note that, although NM is not a global optimization algorithm, it tends to function effectively for situations with few local minima in practice. The NM possibilities are controlled by four main parameters, similar to the DE algorithm: reflection, expansion, contraction, and shrinkage.

The prominent characteristic of the NM algorithm is that it produces satisfactory results after the first few iterations. Furthermore, only one or two function evaluations are required for each iteration, which is exceedingly infrequent in practice. The simplex can change its orientation, size, and shape to adapt to the local contour of the objective function to prevent expensive or time-consuming multiple function evaluations. NM also has much flexibility when it comes to investigating complicated search spaces (Ozturk, Aydin, \& Celik, 2018).

\subsubsection{Random Search algorithm}

The Random Search (RS) algorithm is based on a stochastic approach, often known as the Monte Carlo Method. Because of the algorithm's stochastic character, it differs from deterministic methods like Branch-Bound and Interval Analysis. The main advantages of RS are that(i) it can easily be combined with proper search procedures when the absolute maximum of a multimodal function is required. (ii) It can be used to find the global optimum for non-convex, non-differentiable objective functions in continuous and/or discrete domains. (iii) It is simple to apply to complex optimization problems. (iv) The RS algorithm is relatively robust and provides essential information quickly for ill-defined functions (Karnopp, 1963; Zabinsky, 2009).

\subsubsection{Simulated Annealing algorithm}

The Simulated Annealing algorithm simulates the metal annealing process. It usually allows the structure to escape a local minimum and investigate the global optimum point. Each iteration in the first step generates a new point at random. The method terminates if the ending requirements are met, and the distance between the new point and the current point is calculated using Boltzmann's probability distribution. The energy of a system in thermal equilibrium at temperature " $\mathrm{T}$ " is implied by the distribution. The probability distribution of Boltzmann can be represented as follows (Rao, 2019):

$$
P(E)=e^{-E /(k T)}
$$

Where, $\mathrm{P}(\mathrm{E})$ is the probability of reaching the energy level $\mathrm{E}$, $\mathrm{k}$ is the Boltzmann constant, and $\mathrm{T}$ is the temperature. SA may address mixed-integer, continuous, and/or discrete types of optimization problems in addition to deterministic or classical optimization techniques. Table 2. also shows the DE, NM, RS, and SA optimization method parameters. 
Table 2. Corresponding options for the DE, NM, RS, and SA optimization algorithms.

\begin{tabular}{l|l|l|l|l}
\hline Options & DE & NM & RS & SA \\
\hline Cross Over fractions & 0.5 & - & - & - \\
\hline Random Seed & 1 & 5 & - & 2 \\
\hline Scaling Factor & 0.6 & - & - & - \\
\hline Tolerance & 0.001 & 0.001 & - & 0.001 \\
\hline Contract Ratio & - & 0.5 & - & - \\
\hline Expand Ratio & - & 2.0 & - & - \\
\hline Reflect Ratio & - & 1.0 & - & - \\
\hline Shrink Ratio & - & 0.5 & - & - \\
\hline Level Iterations & - & - & - & 50 \\
\hline Perturbation Scale & - & - & - & 1.0 \\
\hline
\end{tabular}

\subsection{Problem definition}

The optimal design of a nanocomposite drilling process in light of the methods described as: (i) The data shown in Table 3 were selected from the reference study (Kumar et al., 2020). They modeled the input parameters of the biosensors with BoxBehnken design and regression analysis. (ii) 9 candidate functional structures are proposed for modeling the data of the drilling process and evaluated for their suitability in terms of

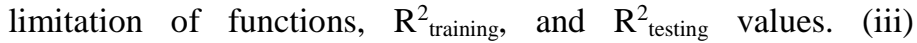
Optimization scenarios are presented by using suitable models obtained for Fd and Th. Finally, these problems are solved by four different direct search methods.

The objective functions in this optimization problem describe the values of $\mathrm{Fd}$ and $\mathrm{Th}$ in the nanocomposite drilling process. The search space is continuous, and all design variables are considered to be real numbers. In this case, $800<$ drill speed (rpm) $<2400,80<$ feed $(\mathrm{mm} / \mathrm{min})<240$, and $1<\mathrm{GO}(\mathrm{wt} \%)<3$. The primary goal is to minimize the $\mathrm{Fd}$ and Th values as much as possible. This method can also be used to find the bounds of the goal function mathematically.
Table 3. Box-Behnken experimental design for independent variables corresponding observed response (Kumar et al., 2020).

\begin{tabular}{c|c|c|c|c|c}
\hline & \multicolumn{3}{|c|}{ Parameters } & \multicolumn{2}{c}{ Responses } \\
\hline $\begin{array}{c}\text { Exp. } \\
\text { No }\end{array}$ & $\begin{array}{c}\text { Drill Speed } \\
(\mathrm{rpm})\end{array}$ & $\begin{array}{c}\text { Feed rate } \\
(\mathrm{mm} / \mathrm{min})\end{array}$ & $\begin{array}{c}\text { GO } \\
(\mathrm{wt} . \%)\end{array}$ & Fd & Th (N) \\
\hline 1 & 800 & 80 & 2 & 1.037 & 64.98 \\
\hline 2 & 2400 & 80 & 2 & 1.020 & 53.94 \\
\hline 3 & 800 & 240 & 2 & 1.103 & 100.81 \\
\hline 4 & 2400 & 240 & 2 & 1.051 & 61.59 \\
\hline 5 & 800 & 160 & 1 & 1.053 & 74.07 \\
\hline 6 & 2400 & 160 & 1 & 1.030 & 57.17 \\
\hline 7 & 800 & 160 & 3 & 1.076 & 95.00 \\
\hline 8 & 2400 & 160 & 3 & 1.042 & 61.29 \\
\hline 9 & 1600 & 80 & 1 & 1.019 & 54.00 \\
\hline 10 & 1600 & 240 & 1 & 1.061 & 68.65 \\
\hline 11 & 1600 & 80 & 3 & 1.037 & 60.84 \\
\hline 12 & 1600 & 240 & 3 & 1.094 & 83.63 \\
\hline 13 & 1600 & 160 & 2 & 1.071 & 67.27 \\
\hline 14 & 1600 & 160 & 2 & 1.057 & 70.00 \\
\hline 15 & 1600 & 160 & 2 & 1.050 & 72.00 \\
\hline
\end{tabular}

\section{Results and Discussion}

The reference study (Kumar et al., 2020) used Box-Behnken design and regression analysis to model the input parameters in the drilling process. Then, using the nonlinear regression models they obtained as an objective function in the SE algorithm, they reached 1.01921 for $\mathrm{Fd}$ and 31.4487 for $\mathrm{Th}$. Both values were obtained at $2400 \mathrm{rpm}, 80 \mathrm{~mm} / \mathrm{min}$, and $1 \mathrm{wt} . \%$ GO parameters. A confirmatory test was performed with these proposed parameters. In this test sample, they found the Fd and Th values as 1.0192 and 31.4487 , respectively.

In the present study, 9 different regression models (see Appendices 1 and 2) with 3 parameters have been tested, and the results are listed in Table 4 and 5.

Table 4. Results of Neuro-Regression models for delamination.

\begin{tabular}{c|c|c|c|c|c|c|c|c}
\hline Models & $\mathbf{R}^{2}$ training & $\mathbf{R}^{2}$ training-adjust & $\mathbf{R}^{2}{ }_{\text {testing }}$ & $\mathbf{R M S E}$ & $\mathbf{M A E}$ & $\mathbf{M E}$ & $\mathbf{M a x}$ & Min \\
\hline $\mathbf{L}$ & 0.9998 & 0.9998 & 0.8205 & 0.0107 & 0.0085 & 0.7929 & 1.1024 & 1.0056 \\
\hline SON & 0.9999 & 0.9998 & 0.9059 & 0.009 & 0.0076 & 0.8523 & 1.1108 & 1.0127 \\
\hline TON & 0.9999 & 0.9998 & 0.951 & 0.0081 & 0.0055 & 0.8813 & 1.2028 & 0.9116 \\
\hline FOT & 0.9996 & 0.9995 & 0.3471 & 0.0195 & 0.016 & 0.3133 & 1.0818 & 1.0214 \\
\hline SOTN & 0.9998 & 0.9995 & -0.1951 & 0.0108 & 0.0079 & 0.7868 & 1.3224 & 0.9218 \\
\hline TOTN & 0.9999 & 1 & -14.8442 & 0.0038 & 0.0016 & 0.9714 & 1.3876 & 0.5377 \\
\hline FOL & 0.9998 & 0.9998 & 0.7823 & 0.0111 & 0.0089 & 0.7751 & 1.0981 & 1.0055 \\
\hline SOLN & 0.9999 & 0.9998 & 0.8918 & 0.0089 & 0.0073 & 0.8553 & 1.1096 & 1.0116 \\
\hline TOLN & 0.9999 & 0.9998 & 0.9337 & 0.0079 & 0.0053 & 0.887 & 1.1978 & 0.9953 \\
\hline
\end{tabular}


Table 5. Results of Neuro-Regression models for thrust force.

\begin{tabular}{c|c|c|c|c|c|c|c|c}
\hline Models & $\mathbf{R}^{2}$ training & $\mathbf{R}^{2}$ training-adjust & $\mathbf{R}^{2}$ testing & $\mathbf{R M S E}$ & $\mathbf{M A E}$ & $\mathbf{M E}$ & Max & Min \\
\hline $\mathbf{L}$ & 0.9946 & 0.9940 & 0.8820 & 5.0261 & 4.2431 & 0.8678 & 99.0654 & 39.7621 \\
\hline SON & 0.9974 & 0.9964 & 0.9897 & 3.4868 & 2.2551 & 0.9363 & 107.441 & 46.1271 \\
\hline TON & 0.9998 & 0.9996 & 0.9928 & 0.9033 & 0.4902 & 0.9957 & 136.063 & 30.061 \\
\hline FOT & 0.9729 & 0.9666 & 0.2029 & 11.3169 & 8.385 & 0.33 & 86.9422 & 49.7221 \\
\hline SOTN & 0.9955 & 0.9818 & -2.4567 & 4.5713 & 3.1682 & 0.8906 & 203.298 & $3.143410^{-11}$ \\
\hline TOTN & 0.9998 & 1 & -4.8119 & 0.8402 & 0.3419 & 0.9963 & 141.777 & $1.210^{-9}$ \\
\hline FOL & 0.9951 & 0.9945 & 0.9148 & 4.8052 & 4.1217 & 0.8792 & 97.9161 & 39.9752 \\
\hline SOLN & 0.9976 & 0.9967 & 0.9829 & 3.3479 & 2.0821 & 0.9413 & 106.787 & 45.7063 \\
\hline TOLN & 0.9998 & 0.9996 & 0.9925 & 0.8980 & 0.4784 & 0.9957 & 129.332 & 30.0514 \\
\hline
\end{tabular}

When Table 4 is examined, 9 different regression models prepared for modeling the delamination process are seen. When the $\mathrm{R}^{2}$ values, limit values and statistical calculation results (RMSE, ME, MAE) of these models were evaluated for model selection, it was seen that the $R^{2}$ training and $R_{\text {training-adjust values in }}^{2}$ the 9 models were very high $(<0.999)$. When the $R^{2}$ testing values were examined, it was determined that the SON, TON, and TOLN models were above the limit value for model selection and below the other models. When the limit values, which is the second criterion, are examined in all three models, it is seen that they are met. When the statistical results, which is the last criterion, were examined, acceptable results were obtained for all three models. It will be used as the objective function in all three regression models for optimization studies.
When analyzed for Table $5, \mathrm{R}_{\text {training }}^{2}$ and $\mathrm{R}_{\text {training adjust }}^{2}$ values are very high for each model. The SON, TON, FOL, SOLN, and TOLN models meet the criteria when the $\mathrm{R}_{\text {testing values are }}^{2}$ analyzed, however the other models do not. The SON, TON, FOL, SOLN, and TOLN models all matched the criteria when the limit values were evaluated. When examining the statistical findings, it is clear that the TON and TOLN models produce better results. In the light of these evaluations, TON and TOLN models will be used as objective functions in the optimization study. The results of the optimization studies performed with four different optimization methods, in which all the models selected for both outputs are used as objective functions, are given in Table 6 and 7. In addition, the optimization result of the reference study is also given in these tables.

Table 6. Optimization results of delamination.

\begin{tabular}{|c|c|c|c|c|c|}
\hline & $\begin{array}{l}\text { Objective } \\
\text { Functions } \\
\end{array}$ & Constraints & $\begin{array}{c}\text { Opt. } \\
\text { Algorithm }\end{array}$ & Delamination & Suggested Design \\
\hline \multirow{12}{*}{$\begin{array}{l}\text { Current } \\
\text { study }\end{array}$} & \multirow[t]{4}{*}{ SON } & \multirow{13}{*}{$\begin{aligned} 800 & <\mathrm{X}_{1}<2400 \\
80 & <\mathrm{X}_{2}<240 \\
1 & <\mathrm{X}_{3}<3\end{aligned}$} & $\mathrm{DE}$ & \multirow{3}{*}{1.0127} & \multirow{3}{*}{$X_{1}=2400, X_{2}=80, X_{3}=1$} \\
\hline & & & RS & & \\
\hline & & & NM & & \\
\hline & & & SA & 1.0178 & $X_{1}=800, X_{2}=80, X_{3}=1$ \\
\hline & \multirow[t]{4}{*}{ TON } & & $\overline{\mathrm{DE}}$ & \multirow{2}{*}{0.8437} & \multirow{2}{*}{$X_{1}=2348.24, X_{2}=240, X_{3}=1$} \\
\hline & & & SA & & \\
\hline & & & RS & 0.6807 & $X_{1}=2400, X_{2}=80, X_{3}=3$ \\
\hline & & & NM & 0.9116 & $\begin{array}{l}X_{1}=800, X_{2}=182.75 \\
X_{3}=2.3288\end{array}$ \\
\hline & \multirow[t]{4}{*}{ TOLN } & & $\overline{\mathrm{DE}}$ & \multirow{3}{*}{0.7623} & \multirow{3}{*}{$X_{1}=2400, X_{2}=80, X_{3}=1$} \\
\hline & & & SA & & \\
\hline & & & RS & & \\
\hline & & & NM & 0.9953 & $\begin{array}{l}\mathrm{X}_{1}=2029.19, \mathrm{X}_{2}=240 \\
\mathrm{X}_{3}=2.5808\end{array}$ \\
\hline Reference & SON & & SA & 1.0192 & $X_{1}=2400, X_{2}=80, X_{3}=1$ \\
\hline
\end{tabular}


Table 7. Optimization results of thrust force.

\begin{tabular}{|c|c|c|c|c|c|}
\hline & $\begin{array}{l}\text { Objective } \\
\text { Functions } \\
\end{array}$ & Constraints & $\begin{array}{c}\text { Opt. } \\
\text { Algorithm }\end{array}$ & Thrust force (Th) & Suggested Design \\
\hline \multirow{8}{*}{$\begin{array}{l}\text { Current } \\
\text { study }\end{array}$} & \multirow[t]{4}{*}{ TON } & \multirow{9}{*}{$\begin{aligned} 800 & <\mathrm{X}_{1}<2400 \\
80 & <\mathrm{X}_{2}<240 \\
1 & <\mathrm{X}_{3}<3\end{aligned}$} & $\mathrm{DE}$ & \multirow{4}{*}{30.061} & \multirow{4}{*}{$X_{1}=2400, X_{2}=80, X_{3}=1$} \\
\hline & & & SA & & \\
\hline & & & NM & & \\
\hline & & & $\mathrm{RS}$ & & \\
\hline & \multirow[t]{4}{*}{ TOLN } & & $\mathrm{DE}$ & \multirow{3}{*}{30.0514} & \multirow{3}{*}{$X_{1}=2400, X_{2}=80, X_{3}=1$} \\
\hline & & & SA & & \\
\hline & & & NM & & \\
\hline & & & RS & 47.152 & $\mathrm{X}_{1}=800, \mathrm{X}_{2}=80, \mathrm{X}_{3}=3$ \\
\hline Reference & $\mathrm{SON}$ & & SA & 31.4487 & $X_{1}=2400, X_{2}=80, X_{3}=1$ \\
\hline
\end{tabular}

Table 6 illustrates the results of the optimization and design parameters for the $\mathrm{Fd}$ values in the nanocomposite drilling process using the regression models that were chosen. In addition, the table also includes the optimization values from the referenced publication for comparison. Table 6 shows that the TON model with the RS algorithm provided the lowest $\mathrm{Fd}$ value of 0.6807 . Then, it was seen that it was estimated as 0.7623 with the DE, SA, and RS algorithms with the TOLN model. The obtained data from the validation test in the reference publication was compared to the optimization results obtained in the current study. As a result of this comparison, the results obtained with the same parameters were obtained as 1.0127 in the SON model with the DE, RS, and $\mathrm{NM}$ algorithms, and as 0.7623 in the TOLN model with the DE, SA, and RS algorithms. When the SON and TOLN models are compared, and the model results are compared to the validation test results, it is clear that the SON model's optimization outcomes are quite near to the real values. While the reference paper used an optimization study to estimate the test value as close as $0.903 \%$, the current study estimated accuracy as close as $0.267 \%$. It is calculated that there is a 3.382 -fold difference between the two estimates.

Table 7 shows the optimization results and design parameters of the Th values in the nanocomposite drilling process with selected regression models. In addition, the optimization values of the referenced publication are added to the table for comparison. The lowest value was obtained at 30.0514 with the TOLN model, DE, SA, and NM algorithms. Then, in the TON model, it was found to be 30.061 with all optimization algorithms. When the results of the confirmatory test performed in the reference publication were compared with the optimization estimates in the current study, the results obtained with the same parameters were estimated with $0.1098 \%$ accuracy in the TON model, with an accuracy of $0.1098 \%$, and in the TOLN model with the DE, SA, and NM algorithms, with an accuracy of $0.0779 \%$. When the TOLN model and the optimization results from the TON and reference study were compared, it was calculated that the accuracy value of the TOLN model was 1.4094, 57.9845 times closer than the TON model and reference study.

\section{Conclusion}

Graphene oxide-based composites are promising candidates for a wide range of industrial applications, particularly for aircraft components, particularly electronics such as supercapacitors, transistors, electrophoresis, gas sensors, and so on. In the final product use of these composites, better surface quality and more precise tolerances are required. It is clear that optimizing the design parameters of the drilling process, which is often preferred, is the most accurate approach. Better surface quality and tighter mechanical tolerances are required in the end product when using these composites. For this reason, it is evident that optimizing the drilling process' design parameters, which is generally selected, is the most accurate way. These approaches make solving the mathematical optimization challenge in the design process more complicated. In order to eliminate these problems, the modelingdesign-optimization process was applied to optimize the $\mathrm{Fd}$ and Th values of nanocomposites. For this purpose, firstly, linear, polynomial, trigonometric and logarithmic models were established. After the model selection phase, optimization studies were carried out using 4 different algorithms (DE, NM, SA, RS) with the selected models. The following are some of the study's major outcomes:

- All nine different models prepared for both Fd and Th are suitable in terms of $\mathrm{R}^{2}$ training and $\mathrm{R}^{2}$ training-adjust values.

- It is seen that the results of the models in terms of $\mathrm{R}^{2}$ testing values for $\mathrm{Fd}$ only provide limit values for the SON, TON, and TOLN models. In addition, an examination was carried out in terms of the stability of the predictions of the models within the limit values, and it is seen that these 3 models give results within the limit values. Furthermore, the fact that the RMSE and MAE values in the statistical findings are close to zero, and the ME value is close to 1 , demonstrates the model's comparability with true values. These three models performed admirably in this regard.

- When the $\mathrm{R}^{2}$ training and $\mathrm{R}^{2}$ training-adjust values of the 9 models created for the Th value are compared, they are all extremely near to 1 . The SON, TON, FOL, SOLN, and TOLN models all match the criteria according to the $\mathrm{R}^{2}$ testing results. These models' limit values are also between the limit values. The TON and TOLN models, on the other hand, have better statistical values than the SON, FOL, and SOLN models.

- In studies conducted for both $\mathrm{Fd}$ and $\mathrm{Th}$, it is seen that logarithmic functions give results with very high values. It is predicted that it can be used as an alternative to polynomial models.

- The results of trigonometric functions could not meet the standards in both $\mathrm{Fd}$ and Th experiments. Within these results, it was seen that the trigonometric functions related to the drilling process were not usable. 
- When the optimization results are examined, the use of 4 different algorithms has revealed that the process can be defined with different approaches. From the optimization result in the reference paper, approximately 3.382 times for the $\mathrm{Fd}$ value and 57.984 times closer to the real result for the $\mathrm{Th}$ value were obtained.

- This is the first time, to our knowledge, that a comprehensive modeling study for the optimal design of the nanocomposite drilling process has been conducted.

\section{References}

Adeniyi, A. G., Ighalo, J. O., \& Onifade, D. V. (2019). Banana and plantain fiber-reinforced polymer composites. Journal of Polymer Engineering, 39(7), 597-611.

Alavitabari, S., Mohamadi, M., Javadi, A., \& Garmabi, H. (2021). The effect of secondary nanofiller on mechanical properties and formulation optimization of HDPE/nanoclay/nanoCaCO3 hybrid nanocomposites using response surface methodology. Journal of Vinyl and Additive Technology, 27(1), 54-67.

Anand, G., Alagumurthi, N., Elansezhian, R., Palanikumar, K., \& Venkateshwaran, N. (2018). Investigation of drilling parameters on hybrid polymer composites using grey relational analysis, regression, fuzzy logic, and ANN models. Journal of the Brazilian Society of Mechanical Sciences and Engineering, 40(4), 1-20.

Aydin, L., \& Artem, H. S. (2011). Comparison of stochastic search optimization algorithms for the laminated composites under mechanical and hygrothermal loadings. Journal of reinforced plastics and composites, 30(14), 1197-1212.

Caggiano, A. (2018). Machining of fibre reinforced plastic composite materials. Materials, 11(3), 442.

Equbal, A., Shamim, M., Badruddin, I. A., Equbal, M., Sood, A. K., Nik Ghazali, N. N., \& Khan, Z. A. (2020). Application of the combined ANN and GA for multi-response optimization of cutting parameters for the turning of glass fiber-reinforced polymer composites. Mathematics, 8(6), 947.

Erten, H. I., Deveci, H. A., \& Artem, H. S. (2020). Stochastic optimization methods: CRC Press.

Ferreira, F., Brito, F., Franceschi, W., Simonetti, E., Cividanes, L., Chipara, M., \& Lozano, K. (2018). Functionalized graphene oxide as reinforcement in epoxy based nanocomposites. Surfaces and Interfaces, 10, 100-109.

Hareesha, M., Yogesha, B., Naik, L. L., \& Saravanabavan, D. (2021). Development on graphene based polymer composite materials and their applications $-A$ recent review. Paper presented at the AIP Conference Proceedings.

Hou, W., Gao, Y., Wang, J., Blackwood, D. J., \& Teo, S. (2020). Recent advances and future perspectives for graphene oxide reinforced epoxy resins. Materials Today Communications, 23, 100883.

Idumah, C. I., \& Obele, C. M. (2021). Understanding interfacial influence on properties of polymer nanocomposites. Surfaces and Interfaces, 22, 100879.

Karnopp, D. C. (1963). Random search techniques for optimization problems. Automatica, 1(2-3), 111-121.

Kesarwani, S., Pratap, P., Kumar, J., Verma, R. K., \& Singh, V. K. (2021). An integrated approach for machining characteristics optimization of polymer nanocomposites. Materials Today: Proceedings, 44, 2638-2644.

Khan, S. U., \& Kim, J.-K. (2011). Impact and delamination failure of multiscale carbon nanotube-fiber reinforced polymer composites: a review. International Journal of Aeronautical and Space Sciences, 12(2), 115-133.

Kharwar, P. K., \& Verma, R. K. (2021). Nature instigated Grey wolf algorithm for parametric optimization during machining (Milling) of polymer nanocomposites. Journal of Thermoplastic Composite Materials, 0892705721993202.

Kim, T., Park, C., Samuel, E. P., An, S., Aldalbahi, A., Alotaibi, F., . . Yoon, S. S. (2021). Supersonically Sprayed Washable, Wearable, Stretchable, Hydrophobic, and Antibacterial rGO/AgNW Fabric for Multifunctional Sensors and Supercapacitors. ACS Applied Materials \& Interfaces, 13(8), 10013-10025.

Kumar, J., \& Verma, R. K. (2021a). Experimental investigation for machinability aspects of graphene oxide/carbon fiber reinforced polymer nanocomposites and predictive modeling using hybrid approach. Defence Technology, 17(5), 16711686.

Kumar, J., \& Verma, R. K. (2021b). A New Criterıon For Drıllıng Machinability Evaluation Of Nanocomposites Modified By Graphene/Carbon Fiber Epoxy Matrix And Optımızation Using Combined Compromise Solution. Surface Review and Letters, 2150082.

Kumar, J., \& Verma, R. K. (2021c). A novel methodology of Combined Compromise Solution and Principal Component Analysis (CoCoSo-PCA) for machinability investigation of graphene nanocomposites. CIRP Journal of Manufacturing Science and Technology, 33, 143-157.

Kumar, J., Verma, R. K., \& Debnath, K. (2020). A new approach to control the delamination and thrust force during drilling of polymer nanocomposites reinforced by graphene oxide/carbon fiber. Composite Structures, 253, 112786.

Lawal, A. T. (2020). Recent progress in graphene based polymer nanocomposites. Cogent Chemistry, 6(1), 1833476.

Moghri, M., Madic, M., Omidi, M., \& Farahnakian, M. (2014). Surface roughness optimization of polyamide-6/nanoclay nanocomposites using artificial neural network: genetic algorithm approach. The Scientific World Journal, 2014.

Nelder, J. A., \& Mead, R. (1965). A simplex method for function minimization. The computer journal, 7(4), 308-313.

Ozturk, S., Aydin, L., \& Celik, E. (2018). A comprehensive study on slicing processes optimization of silicon ingot for photovoltaic applications. Solar Energy, 161, 109-124.

Papageorgiou, D. G., Kinloch, I. A., \& Young, R. J. (2017). Mechanical properties of graphene and graphene-based nanocomposites. Progress in Materials Science, 90, 75-127.

Papageorgiou, D. G., Li, Z., Liu, M., Kinloch, I. A., \& Young, R. J. (2020). Mechanisms of mechanical reinforcement by graphene and carbon nanotubes in polymer nanocomposites. Nanoscale, 12(4), 2228-2267.

Pramanik, S., Kumar, Y., Gupta, D., Vashistha, V. K., Kumar, A., Karmakar, P., \& Das, D. K. (2021). Recent advances on structural and functional aspects of multi-dimensional nanoparticles employed for electrochemically sensing biomolecules of medical importance. Materials Science and Engineering: B, 272, 115356.

Rao, S. S. (2019). Engineering optimization: theory and practice: John Wiley \& Sons.

Roshan, H., Sheikhi, M. H., Haghighi, M. K. F., \& Padidar, P. (2019). High-performance room temperature methane gas sensor based on lead sulfide/reduced graphene oxide nanocomposite. IEEE Sensors Journal, 20(5), 2526-2532.

Sanes, J., Sánchez, C., Pamies, R., Avilés, M.-D., \& Bermúdez, M.-D. (2020). Extrusion of polymer nanocomposites with 
graphene and graphene derivative nanofillers: An overview of recent developments. Materials, 13(3), 549.

Saoudi, J., Zitoune, R., Mezlini, S., Gururaja, S., \& Seitier, P. (2016). Critical thrust force predictions during drilling: analytical modeling and X-ray tomography quantification. Composite Structures, 153, 886-894.

Savran, M., \& Aydin, L. (2018). Stochastic optimization of graphite-flax/epoxy hybrid laminated composite for maximum fundamental frequency and minimum cost. Engineering Structures, 174, 675-687.

Sharma, A. K., Bhandari, R., Aherwar, A., \& Rimašauskienè, R. (2020). Matrix materials used in composites: A comprehensive study. Materials Today: Proceedings, 21, 1559-1562.

Soleymani Eil Bakhtiari, S., Bakhsheshi-Rad, H. R., Karbasi, S., Tavakoli, M., Razzaghi, M., Ismail, A. F., . . . Berto, F. (2020). Polymethyl methacrylate-based bone cements containing carbon nanotubes and graphene oxide: An overview of physical, mechanical, and biological properties. Polymers, 12(7), 1469.

Srinivasan, S., Thirumurugaveerakumar, S., Nagarajan, N., Raffic, N. M., \& Babu, K. G. (2021). A review of optimization techniques in machining of composite materials. Materials Today: Proceedings.

Suriani, M., Radzi, F. S. M., Ilyas, R., Petrů, M., Sapuan, S., \& Ruzaidi, C. (2021). Flammability, Tensile, and Morphological Properties of Oil Palm Empty Fruit Bunches Fiber/Pet Yarn-Reinforced Epoxy Fire Retardant Hybrid Polymer Composites. Polymers, 13(8), 1282.

Thakur, R., \& Singh, K. (2021). Influence of fillers on polymeric composite during conventional machining processes: a review. Journal of the Brazilian Society of Mechanical Sciences and Engineering, 43(2), 1-20.

Wang, M., Tang, X.-H., Cai, J.-H., Wu, H., Shen, J.-B., \& Guo, S.-Y. (2021). Construction, mechanism and prospective of conductive polymer composites with multiple interfaces for electromagnetic interference shielding: a review. Carbon.

Yu, R., \& Pandolfi, A. (2008). Modeling of delamination fracture in composites: a review. Delamination behaviour of composites, 429-457.

Yu, W., Sisi, L., Haiyan, Y., \& Jie, L. (2020). Progress in the functional modification of graphene/graphene oxide: A review. RSC Advances, 10(26), 15328-15345.

Zabinsky, Z. B. (2009). Random search algorithms. Department of Industrial and Systems Engineering, University of Washington, USA. 